\title{
Updraft and downdraft characterization with Doppler lidar: cloud-free versus cumuli-topped mixed layer
}

\author{
A. Ansmann, J. Fruntke, and R. Engelmann \\ Leibniz Institute for Tropospheric Research, Permoserstr. 15, 04318 Leipzig, Germany \\ Received: 12 March 2010 - Published in Atmos. Chem. Phys. Discuss.: 13 April 2010 \\ Revised: 23 July 2010 - Accepted: 6 August 2010 - Published: 24 August 2010
}

\begin{abstract}
For the first time, a comprehensive, heightresolved Doppler lidar study of updrafts and downdrafts in the mixing layer is presented. The Doppler lidar measurements were performed at Leipzig, Germany, in the summer half year of 2006. The conditional sampling method is applied to the measured vertical velocities to identify, count, and analyze significant updraft and downdraft events. Three cases of atmospheric boundary-layer (ABL) evolution with and without fair-weather cumuli formation are discussed. Updrafts occur with an average frequency of 1-2 per unit length $z_{i}$ (boundary-layer depth $z_{i}$ ), downdrafts 20-30\% more frequently. In the case with cumuli formation, the draft occurrence frequency is enhanced by about $50 \%$ at cloud level or near cloud base. The counted updraft events cover $30-34 \%$, downdrafts $53-57 \%$ of the velocity time series in the central part of the ABL (subcloud layer) during the main period of convective activity. By considering all drafts with horizontal extent $>36 \mathrm{~m}$ in the analysis, the updraft mean horizontal extent ranges here from $200-420 \mathrm{~m}$ and is about $0.16 z_{i}-0.18 z_{i}$ in all three cases disregarding the occurrence of cumulus clouds. Downdraft extents are a factor of 1.31.5 larger. The average value of the updraft mean vertical velocities is $0.5-0.7 \mathrm{~m} / \mathrm{s}$ or $0.40 w_{*}-0.45 w_{*}$ (convective velocity scale $w_{*}$ ), and the negative downdraft mean vertical velocities are weaker by roughly $10-20 \%$. The analysis of the relationship between the size (horizontal extent) of the updrafts and downdrafts and their mean vertical velocity reveals a pronounced increase of the average vertical velocity in updrafts from $0.4-0.5 \mathrm{~m} / \mathrm{s}$ for small thermals $(100-200 \mathrm{~m})$ to about $1.5 \mathrm{~m} / \mathrm{s}$ for large updrafts $(>600 \mathrm{~m})$ in the subcloud layer in the case with fair-weather cumuli. At cloudless conditions, the updraft velocities were found to be $20 \%$ smaller for the large thermals.
\end{abstract}

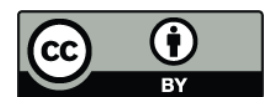

Correspondence to: A. Ansmann (albert@ tropos.de)

\section{Introduction}

It is well known that vertical mixing of heat, moisture, momentum, aerosols, and gaseous pollution in the unstable atmospheric boundary layer (ABL) is predominantly carried out by motions occurring within discrete elements of considerable vertical extent (Lenschow, 1970; Lenschow and Stephens, 1980; Greenhut and Khalsa, 1982, 1987; Khalsa and Greenhut, 1985; Young, 1988a,b,c). Convectively driven updrafts formed by coalescence of smaller surface-based buoyant elements often extend through the depth of the wellmixed layer. Coherent thermals up to $4 \mathrm{~km}$ height above ground were observed over desert areas (Ansmann et al., 2009). Thermals of sufficient size and buoyancy reaching the capping inversion penetrate into the stable layer above and cause dry air intrusions which sometimes reach heights close to the surface in form of well-organized downdrafts. These upward and the compensating downward motions are responsible for an efficient vertical exchange in the ABL. Therefore, field observations of the number frequency of occurring updrafts and surrounding downdraft areas, their typical horizontal extents and strengths in terms of updraft and downdraft mean vertical velocities provide valuable information to improve our understanding of the physical processes of organized convection in the ABL and to further improve and validate vertical flux schemes of atmospheric models.

Boundary-layer clouds such as fair-weather cumuli (cumulus humilis, mediocris, congestus) have a significant impact on the vertical transport characteristics (Young, 1988c; Cotton et al., 1995; Kollias et al., 2001; Vilà-Guerau de Arellano et al., 2005). The interaction between boundary-layer cumulus clouds and thermals which initiate them is of considerable importance not only to the turbulence structure of the convective boundary layer but also to the venting of pollutants into the free atmosphere and the triggering of deep moist convection. Active cumulus (e.g., cumulus congestus) with an additional energy source due to the release of latent

Published by Copernicus Publications on behalf of the European Geosciences Union. 
heat enhances mixed-layer turbulence and can thus significantly alter the updraft profile. Representing these processes realistically in atmospheric models including the development of appropriate cloud parameterizations continues to be a challenging task (Jakob and Siebesma, 2003; Soares et al., 2004; Angevine, 2005; Verzijlbergh et al., 2009).

To better understand this complex field of atmospheric physics, more updraft/downdraft field observations are required. Studies under very different meteorological conditions, for different weather regimes, at maritime and continental sites, in rural and urban environments, over flat and orographically complex terrain are useful. More than 20 years after the pioneering work by Lenschow, Greenhut, Khalsa, and Young, a first comprehensive lidar-based study of updraft and downdraft occurrence frequencies, occurrence durations, corresponding horizontal extents, and mean vertical velocities of updrafts and downdrafts is presented. In contrast to airborne in situ observations (Lenschow and Stephens, 1980; Greenhut and Khalsa, 1982; Khalsa and Greenhut, 1985; Godowitch, 1986; Young, 1988b; Williams and Hacker, 1992; Durand et al., 2000; Said et al., 2009), Doppler lidar allows us to monitor the entire mixed layer including the entrainment zone vertically resolved and continuously over long time periods so that a detailed study of the full evolution cycle of the ABL over the day is possible (Grund et al., 2001; Bösenberg and Linné, 2002; Drobinski et al., 2004; Wulfmeyer and Janjić, 2005; Lothon et al., 2006; Gibert et al., 2007; Engelmann et al., 2008; Hogan et al., 2009).

During the Aerosol Vertical ExChange 2006 (AVEC 2006) campaign from March to November 2006, we observed more than 70 diurnal cycles of the ABL evolution with a zenithpointing Doppler lidar in flat terrain at a central European urban site (Leipzig, Germany). The Doppler lidar measures height profiles of the vertical wind component with a temporal and vertical resolution of $5 \mathrm{~s}$ and $75 \mathrm{~m}$. In this paper we study the ABL updraft and downdraft characteristics of three cases following the strategy suggested by Young (1988b). The frequency of occurrence of updrafts and downdrafts, their occurrence duration and corresponding horizontal extent, the vertical velocities in the drafts as well as the relationship between the draft mean velocity and draft horizontal size are investigated. We extend the traditional discussion by contrasting the findings for a cloud-free case and a case with fair-weather cumuli formation. The selected three cases can be regarded as representative for many summertime ABL developments over Leipzig.

In Sect. 2, the AVEC campaign, the Doppler lidar, and the data analysis method are explained. Section 3 presents the results of the three case studies of ABL evolution. A summary and concluding remarks are given in Sect. 4.

\section{Experiment}

In the framework of AVEC 2006, for the first time wellcoordinated observations of the vertical flux of atmospheric aerosol particles were performed by utilizing a wind Doppler lidar in synchronized combination with a multiwavelength aerosol Raman lidar (Engelmann et al., 2008). AVEC 2006 took place at Leipzig $\left(51.4^{\circ} \mathrm{N}, 12.4^{\circ} \mathrm{E}, 120 \mathrm{~m}\right.$ above sea level, rather flat terrain) from 1 March to 31 October 2006. As part of AVEC 2006, Baars et al. (2008) analyzed one-year observations of the ABL evolution with a quasi continuously running automated aerosol lidar and present statistics on the daytime ABL-top height $z_{i}$ and $z_{i}$ growth rates. The third goal of AVEC 2006 is the detailed characterization of ABL turbulent motions in terms of updraft and downdraft properties.

The utilized Doppler lidar measures the vertical velocity of aerosol particles and thus of air parcels from $400 \mathrm{~m}$ above the ground to the top of the ABL with $5 \mathrm{~s}$ temporal and $75 \mathrm{~m}$ vertical resolution as mentioned. The lidar is described in detail by Engelmann et al. (2008) and Engelmann (2009). The transmitted wavelength is $2.022 \mu \mathrm{m}$. The zero wind speed is checked from time to time by pointing the laser beam to a building. The remaining uncertainty after this calibration is estimated to be $0.05 \mathrm{~m} / \mathrm{s}$. The overall uncertainty in the determination of the vertical velocity is of the order of 0.10 $0.15 \mathrm{~m} / \mathrm{s}$, taking an uncertainty of $0.05 \mathrm{~m} / \mathrm{s}$ in the signal processing and a similar uncertainty resulting from the pointing uncertainty of $0.2^{\circ}$ into account. The vertical alignment is often checked by rocking over the zenith from $-2^{\circ}$ to $+2^{\circ}$ and searching for the peak in the backscatter signal caused by specular reflections when cirrus is present (Seifert et al., 2008).

Signal noise accounts for uncertainties of $<0.1 \mathrm{~m} / \mathrm{s}$ in the vertical velocity retrieval for signal-to-noise levels as used in this study. The influence of signal noise was investigated several times during the development of the lidar system. In this approach the random error is estimated from the auto covariance noise peak and from high frequency levels in the vertical-velocity spectrum (see e.g. Frehlich (2001)).

The basic data analysis (noise filtering, signal digitization, fast Fourier transformation, spectral peak finding) to determine the wind speed is presented by Engelmann (2009) and Fruntke (2009). From the wind data set we removed outliers, i.e., unrealistic clear air vertical wind values of $>10 \mathrm{~m} / \mathrm{s}$ and $<-10 \mathrm{~m} / \mathrm{s}$ and wind speed values that differed significantly from neighboring values.

We applied the conditional sampling technique (Greenhut and Khalsa, 1982, 1987; Young, 1988b) to the remaining data set to identify the updraft and downdraft regions and to estimate their horizontal and vertical extent. A data sequence is counted as updraft or downdraft event when the condition

$w(t)>0.1 \mathrm{~m} / \mathrm{s}$ 
or

$w(t)<-0.1 \mathrm{~m} / \mathrm{s}$

is fulfilled for $t \geq 20 \mathrm{~s}$. $w$ is the verticval velocity. For the mean value we assume $\bar{w}=0$ and check this assumption by averaging wind velocities in the early morning hours before the evolution of the ABL or late evening hours after the formation of the residual layer. During the evolution of the ABL (active phase), such a check is not possible. Mean values of the vertical velocity were typically in the range from -0.05 to $-0.25 \mathrm{~m} / \mathrm{s}$ during AVEC 2006, indicating that, on average, more downdraft than updraft areas crossed the lidar field site (see discussion below). Additionally, surface heterogeneity (buildings, streets, villages, fields) may have contributed to the observed mostly negative mean vertical velocities (Patton et al., 2005; van Heerwaarden and Vilà-Guerau de Arellano, 2008).

The threshold value of $w=0.1 \mathrm{~m} / \mathrm{s}$ allows us to concentrate on the significant updrafts and downdrafts. The choice of a $w$ threshold and a minimum width controls the differentiation of thermals from regions of mesoscale ascents (of a few $\mathrm{cm} / \mathrm{s}$ ) and from small-scale fluctuations on thermals (Young, 1988b). Those remaining data points in the time series that satisfy neither the criteria for thermal updraft nor between-thermal downdraft are grouped into a third category called environmental air (Stull, 1988).

By flying cross and parallel to the main wind directions, Williams and Hacker (1992) showed that the horizontal cross sections of updraft and downdraft zones depend on flight leg (perpendicular or parallel to the wind direction) in the surface layer (at heights $<0.1 z_{i}$ ) but not in the mixing layer $\left(>0.3 z_{i}\right)$, so that ground-based lidar observations (parallel to the main wind direction) in the mixing layer provide a trustworthy view into the updraft and downward characteristics.

Among the set of quantities characterizing the turbulent state of the boundary layer, the vertical velocity variance $\sigma_{w}^{2}$, skewness $s_{w}$, and kurtosis $k_{w}$ defined as

$\sigma_{w}^{2}(z)=\overline{w^{\prime}(z)^{2}}$

$s_{w}(z)=\overline{\left(\frac{w^{\prime}(z)}{\sigma_{w}(z)}\right)^{3}}$

$k_{w}(z)=\overline{\left(\frac{w^{\prime}(z)}{\sigma_{w}(z)}\right)^{4}}-3$

are used. Here, $w^{\prime}=w-\bar{w}$. Note that $s_{w}=0$ and $k_{w}=0$ for an ideal Gaussian distribution according to Eq. (5).

An important quantity in the description of convective motions is the convective velocity scale $w_{*}$. The vertical velocity scale is estimated by applying the relationship (Lenschow and Stephens, 1982)

$\sigma_{w}^{2}(z)=1.8 w_{*}^{2}\left(\frac{z}{z_{i}}\right)^{\frac{2}{3}}\left(1-0.8 \frac{z}{z_{i}}\right)^{2}$ with height $z$ and the mixing-layer depth $z_{i}$. The measured profile of $\sigma_{w}^{2}(z)$ is compared to respective $\sigma_{w}^{2}(z)$ profiles computed after Eq.(6) for a large set of $z_{i}$ and $w_{*}$ pairs. The most appropriate curve and respective values for $z_{i}$ and $w_{*}$ are found by fitting (non-linear least squares fit) the modelled curve (Eq. 6) to the measured profile of $\sigma_{w}^{2}(z)$ (Eq. 3). The analysis is facilitated if the mixing-layer depth $z_{i}$ is known from a simultaneously running aerosol lidar (Baars et al., 2008) or ceilometer so that only $w_{*}$ remains to be determined. As outlined in Stull (1988) the whole process of vertical mixing is a circulation that moves air up and down in the mixed layer with a time period on the order of $t_{*}=z_{i} / w_{*}$ in the case of surface-heating-driven convection. For $z_{i}=1000 \mathrm{~m}$ and $w_{*}=1 \mathrm{~m} / \mathrm{s}$, we obtain $t_{*}=1000 \mathrm{~s}$, i.e., about $15 \mathrm{~min}$ are needed for one full circle.

\section{Results}

\subsection{Meteorological and turbulence characteristics}

Figure 1 shows the three selected cases. Corresponding radiosonde observations of meteorological parameters at 12:00 UTC (14:00 Local Time, LT) are presented in Fig. 2. The routine observations of the German Meteorological Service were performed at Meiningen, about $170 \mathrm{~km}$ southwest of Leipzig. All data are given for heights above sea level (a.s.1.).

The ABL developed over rather flat terrain. Buildings (mostly with heights $<25 \mathrm{~m}$ ), streets, and open areas such as parks, gardens, and parking areas determine the surface conditions $5 \mathrm{~km}$ (5 April, 5 May) to $10 \mathrm{~km}$ (18 September) upwind the suburban lidar site. Villages and fields (almost no forest) and few lakes are typical for distances $>5-10 \mathrm{~km}$ (outside of Leipzig).

To provide some information on the evolution of surface forcing over the day for the three cases we analyzed continuous meteorological observations at Melpitz (flat terrain, extended grassland, $50 \mathrm{~km}$ northeast of Leipzig; Spindler et al., 2001). The sensible heat flux, measured with a fast ultrasonic anemometer (3-dimensional wind field, temperature) at $5 \mathrm{~m}$ above ground was $0-50 \mathrm{~W} / \mathrm{m}^{2}$ before 06:00-07:00 LT and after 18:00-19:00 LT, and steadily increased to values around $250 \mathrm{~W} / \mathrm{m}^{2}$ (5 April), 150-200 W/m ${ }^{2}$ (5 May), and 200$250 \mathrm{~W} / \mathrm{m}^{2}$ (18 September) around noon (12:00-13:00 LT), before the flux decreased to low values again. Because of the strong differences in surface roughness (Melpitz versus Leipzig) and soil moisture conditions, estimates for the latent heat flux are not presented. The decrease of the water vapor pressure by 0.1 (5 April, 18 September) to $0.35 \mathrm{hPa} / \mathrm{m}$ (5 May) for the range from 2-8 $\mathrm{m}$ above ground at Melpitz around noon may however indicate a non-negligible latentheat-flux contribution to surface forcing. Regarding soil moisture, 5-101/ $\mathrm{m}^{2}$ of rain were registered at Leipzig for the period from 2-4 April. Rather dry and sunny conditions 
prevailed within the week before the measurements on 5 May and 18 September 2006. The aerosol optical depth $(500 \mathrm{~nm}$ wavelength) was around 0.05-0.1 (5 April), 0.3 (5 May), and 0.2 (18 September).

As can be seen in Fig. 1, a 2-2.5 km deep, cloud-free ABL developed on 5 May 2006. A high-pressure system over Scandinavia and a low-pressure system over southeastern Europe caused advection of dry eastern European air to the lidar field site. Easterly winds with velocities around $10 \mathrm{~m} / \mathrm{s}$ prevailed in the mixing layer (above $500 \mathrm{~m}$ ) up to the boundary layer top $z_{i}$ according to atmospheric modeling results (data archive of the U.S. National Weather Service's National Center of Environmental Prediction based on the Global Data Analysis System, GDAS, http://www.arl.noaa.gov/fnl.php). The wind profiles (snapshot-like observation) of Meiningen in Fig. 2 are not used in the analysis of the Doppler lidar data in Sect. 3.2 and 3.3. The Meiningen radiosonde profiles for the virtual potential temperature and dew point show well-mixed conditions in the ABL on 5 May, 14:00 LT. The strong increase of the ABL top of about $1000 \mathrm{~m}$ from 10:00-12:00 LT indicates strong entrainment of dry, free tropospheric air into the ABL.

On 18 September 2006 (see Fig. 1, center panel), the air mass was advected from southerly to westerly directions under the influence of a weak, dissolving low-pressure system over eastern Germany. Wind speeds were low with values of $<2 \mathrm{~m} / \mathrm{s}$ in the boundary layer over Leipzig according to the GDAS data. An optically thin lofted Saharan dust layer $(0.1$ optical depth at $500 \mathrm{~nm}$ ) from $2-4 \mathrm{~km}$ height may have weakly influenced the ABL development before 13:00 LT. Yu et al. (2002) and Wendisch et al. (2008) investigated the potential impact of light-scattering and absorbing aerosols on the evolution of the ABL. In these studies, the particle optical depth at $500 \mathrm{~nm}$ ranges from $0.5-1.0$ and the aerosol influence is considerable. Measurements in Saharan dust in southern Morocco (Ansmann et al., 2009) suggest however that dust optical depths $<0.3$ do not have any significant impact on the reduction of surface heating, changes of the vertical temperature gradient, and thus on the evolution of convective plumes. This finding is corroborated by the fact that an almost monotonic, linear increase of the sensible heat flux from 06:00-12:00 LT was observed at Melpitz on 18 September.

The 5 April case shown in the bottom panel of Fig. 1 represents a typical case of an ABL evolution with fair-weather cumuli formation. Under the influence of a low-pressure system over the Baltic Sea (Denmark, southern Sweden) cold and dry air of polar origin was advected from the North Sea to the field site on that day. Northwesterly winds were weak with wind speeds $<5 \mathrm{~m} / \mathrm{s}$ according to the GDAS data set for grid point Leipzig. Fair-weather cumulus clouds develop one hour after the onset of the ABL evolution. The temperature profiles in Fig. 2 (bottom) indicate well-mixed conditions in the ABL at 14:00 LT. The ABL top height increases by only $300 \mathrm{~m}$ from 10:00-12:00 LT. Entrainment of dry air
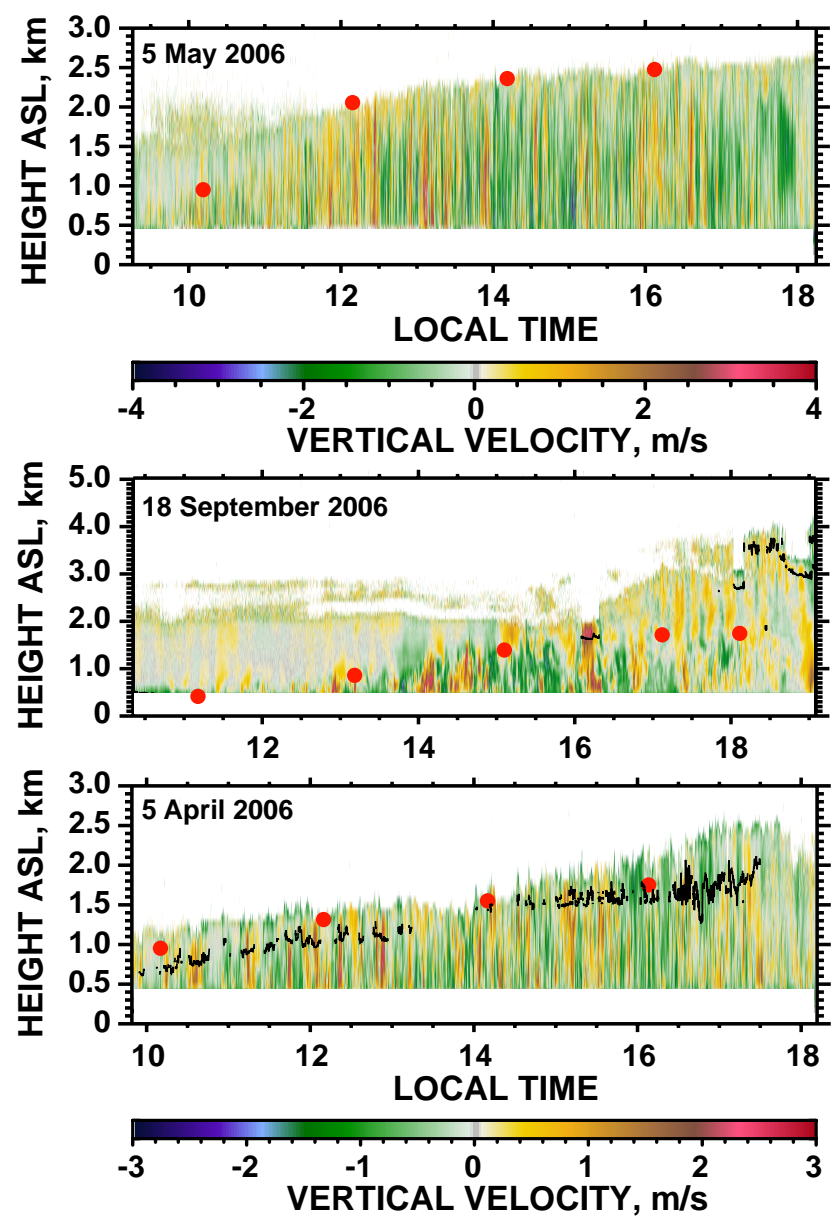

Fig. 1. Evolution of the ABL in terms of vertical velocity observed with Doppler lidar (resolution: $5 \mathrm{~s}, 75 \mathrm{~m}$ ) at Leipzig on 5 May 2006 (top), 18 September 2006 (center), and 5 April 2006 (bottom). Yellow and red (positive velocities) indicate upward movements, whereas green and blue (negative velocities) represent downward movements. Red circles show the general trend in the increase of the ABL top height as observed with an automated aerosol lidar. Cloud base heights of convective clouds are indicated by black lines. Lidar signals from the near range (region of detector saturation) are not trustworthy and thus not shown. 12:00 Local Time (LT, daylight saving time) is 11:00 Central European Time (CET) and 10:00 UTC.

from above was less strong on 5 April, compared to 5 May. The cloud base height increases from 500 to $1500 \mathrm{~m}$ in the late afternoon.

It should be mentioned that the lidar data in Fig. 1 (center and bottom panel) show some contamination by the so-called chirp effect (underestimation of the vertical velocity at cloud top caused by a strong drop of the backscatter signal Dabas et al., 1998; Wulfmeyer et al., 2000), e.g., at $3 \mathrm{~km}$ height on 18 September shortly after 18:00 LT and from 18:30 19:00 LT. To avoid an influence of this effect on the further 


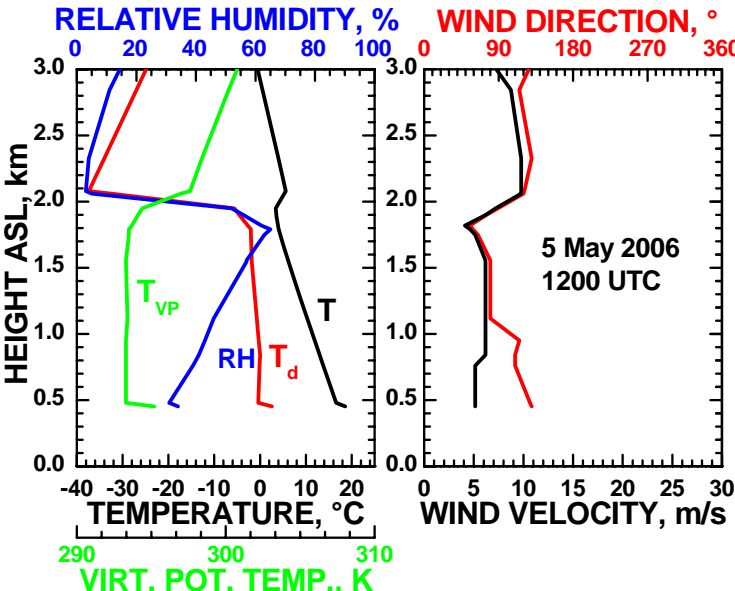

RELATIVE HUMIDITY, \% WIND DIRECTION, 。

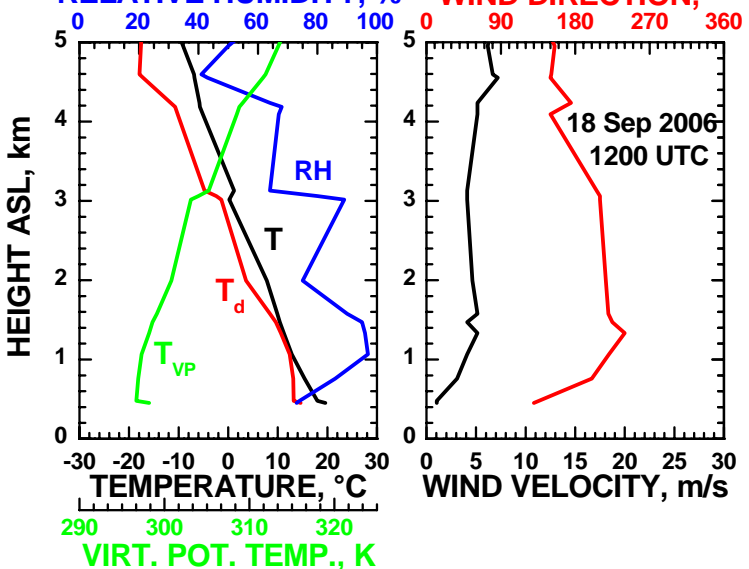

RELATIVE HUMIDITY, \% WIND DIRECTION, ${ }^{\circ}$

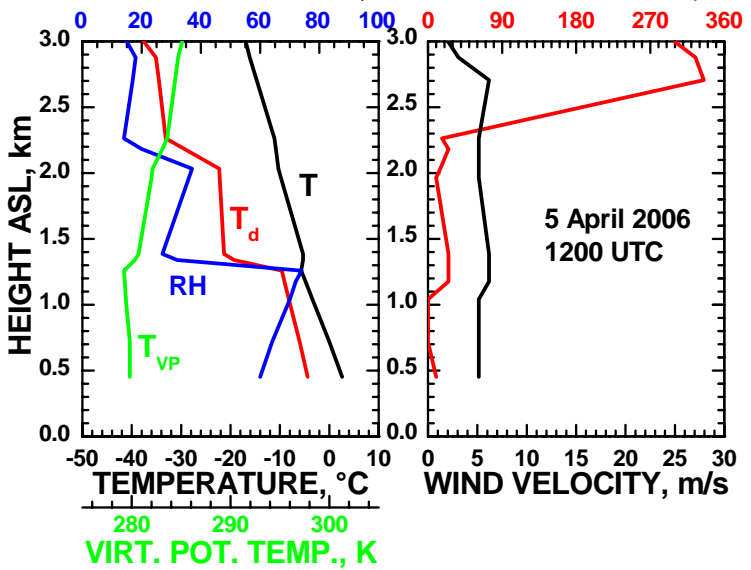

Fig. 2. $12: 00 \mathrm{UTC}$ Meiningen $\left(50.6^{\circ} \mathrm{N}, 10.4^{\circ} \mathrm{E}, 450 \mathrm{~m}\right.$ a.s.1.) radiosonde profiles of temperature $T$, virtual potential temperature $T_{\mathrm{VP}}$, dew point $T_{\mathrm{d}}$, and relative humidity $R H$. The sondes are routinely launched by the German Meteorological Service $170 \mathrm{~km}$ southwest of Leipzig.

data analysis most of the results presented in Sects. 3.2 and 3.3 are given for the $500-1100 \mathrm{~m}$ height range (subcloud layer) only.

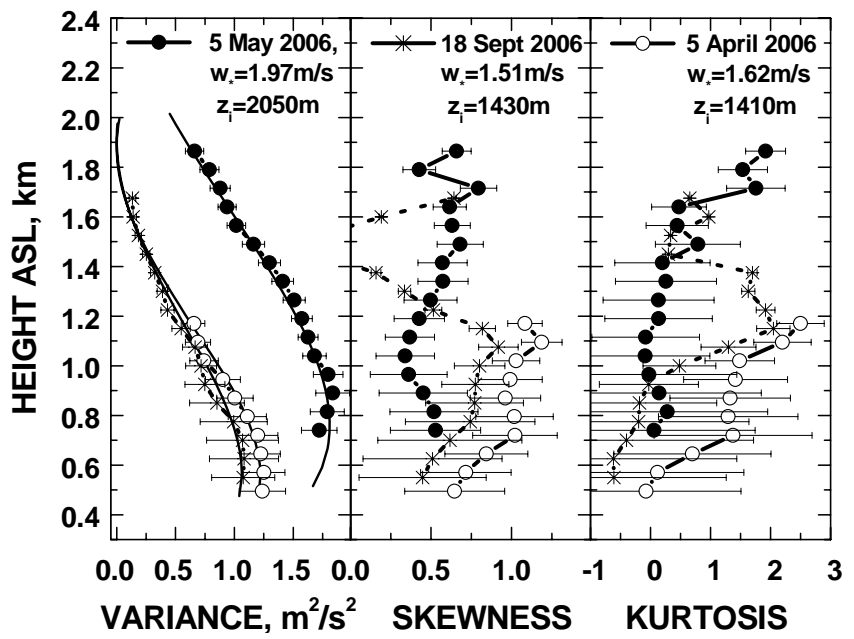

Fig. 3. Variance, skewness, and kurtosis of vertical velocity considering measurements from 12:00-14:00 LT on 5 April and 5 May 2006, and from 14:00-16:00 LT on 18 September 2006. Error bars indicate sampling errors calculated after Lenschow et al. (1994). Instrumental noise is very low. Values for the convective scale $w_{*}$ and mixing-layer top height $z_{i}$ for the analyzed two-hour periods are given as numbers. The respective variance profiles after Eq. (6) for these $w_{*}$ and $z_{i}$ values are shown as solid lines in the variance plot (left).

Figure 3 presents profiles for the statistical moments (variance, skewness, and kurtosis) computed after Eqs.(3)-(5) for two-hour intervals during phases of strong convection. The vertical velocity variance decreases with height, i.e., with distance from the source of turbulent kinetic energy (TKE) production. $\sigma_{w}^{2}$ is highest on 5 May, the day with the deepest $\mathrm{ABL}$ and the highest $w_{*}$. The uncertainty caused by signal noise is $<0.01 \mathrm{~m}^{2} / \mathrm{s}^{2}$ and thus negligible. Solid lines in the variance plot in Fig. 3 show the variance profiles computed by using Eq. (6).

Skewness is positive which indicates surface-heatingdriven convection and that, in a very idealized sense, broad regions of gentle downdraft surround smaller regions of strong updraft (Moeng and Rotunno, 1990; Hogan et al., 2009). The skewness is significantly higher for the day with fair-weather cumuli development (5 April) than for the cloud-free day (5 May) in agreement with the discussion given by Heus et al. (2009) and Verzijlbergh et al. (2009).

A measure of the peakedness of a distribution is the normalized fourth moment or kurtosis. Positive kurtosis indicates that the distribution of vertical velocity fluctuations in the mixing layer is much more peaked than a Gaussian distribution. The highest kurtosis values are found on the day with fair-weather cumuli.

Figure 4 shows histograms of vertical velocities for 645 and $1095 \mathrm{~m}$ height a.s.l. measured on 5 April 2006 from 09:49-16:45 LT (almost for the entire measurement period 


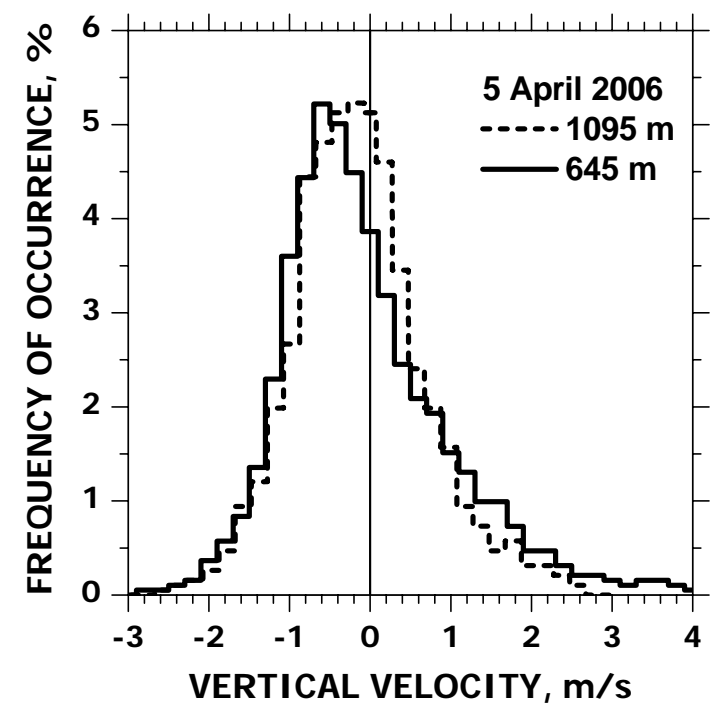

Fig. 4. Frequency of occurrence of vertical velocity measured with Doppler lidar on 5 April from 09:49-16:45 LT. Distributions are presented for $645 \mathrm{~m}$ height a.s.l. (lower ABL) and $1095 \mathrm{~m}$ height a.s.1. (upper ABL before 14:00 LT).

in Fig. 1). Measurements after 16:45 LT, when a compact almost closed stratocumulus field was present over the field site above $1620 \mathrm{~m}$ height, are not considered. Both distributions in Fig. 4 are shifted to the left. This shift is caused by the occurrence of a large number of weak interthermal downdrafts, and a small frequency of strong thermal updrafts (Stull, 1988). The skewness (positive after Eq. (4) in this case) decreases with height. The velocity distribution tends to become more symmetric.

\subsection{Updraft and downdraft statistics}

Figure 5 presents an idealized and simple sketch in order to illustrate what a Doppler lidar is detecting. In the case of easterly winds, the lidar is monitoring the ABL evolution along the arrow pointing to the east in Fig. 5, and updraft and downdraft areas cross the lidar site from east to west. The arrangement and relative sizes of updraft and downdraft areas in this simplified sketch reflect qualitatively the findings presented in Fig. 6 for the cumuli-topped case (5 April). As illustrated in Fig. 5 updraft cross sections are smaller than downdraft areas which surround these thermals. Downdraft areas may be regarded as diffuse regions (with no clear boundaries), which may often merge, and which are sometimes interrupted by areas with velocities from 0.1 to $-0.1 \mathrm{~m} / \mathrm{s}$ (environmental air).

By using Eqs. (1) and (2) we analyzed the time series of the vertical velocity $w$ to identify the updraft and downdraft events at different height levels from $525 \mathrm{~m}$ height up to the ABL top height $z_{i}$. We analyzed the time series from the beginning of convective activity to the end of the ABL life-

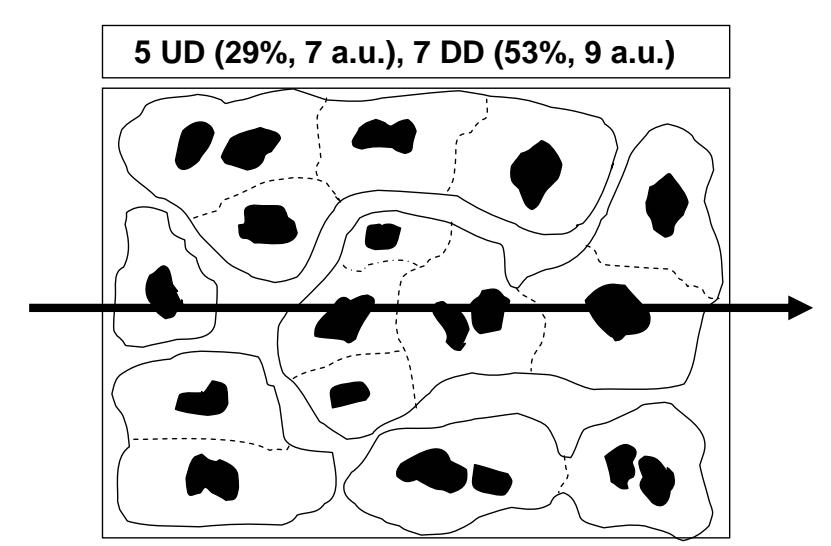

Fig. 5. Top view on the convectively active ABL. The idealized scenario is in qualitative agreement with Figure 6. Well-defined small areas of updrafts (UD, black) are surrounded by zones with downward motion (DD, white). The DD zones partly merge (indicated by dashed lines). The thick horizontal vector, pointing to the east, illustrates what a Doppler lidar observes in case of easterly winds regarding draft frequency (5 UD, 7 DD zones), occurrence duration or horizontal extent (updraft mean extent of 7 arbitrary units, a.u., downdraft mean extent of 9 a.u.), and how much of the area is covered by updrafts $(29 \%)$ and by downdraft zones $(53 \%)$. The remaining area $(18 \%)$ is covered by environmental air $(-0.1 \mathrm{~m} / \mathrm{s}<w<0.1 \mathrm{~m} / \mathrm{s})$.

time as well as for the convectively most active period from 12:00-17:00 LT (see Fig. 1).

Figure 6 presents the statistics of updraft and downdraft events observed on 5 April. On average, 15 updrafts and 20 downdrafts per hour are counted over the entire day. At cloud level (1095 m height a.s.l., cloud formation occurred here before 13:30 LT) the updraft occurrence frequency is significantly increased and exceeds the value of the downdraft frequency. Cloud occurrence reinforces the convective activity by about $50 \%$ as a result of latent heat release and horizontally and vertically inhomogeneous radiative heating and cooling. The downdraft occurrence frequency, in turn, is enhanced at $1320 \mathrm{~m}$ height a.s.l. This is probably caused by enhanced entrainment of free tropospheric air into the ABL before 13:30 LT triggered by cloud formation. After 13:30 LT, both the $1095 \mathrm{~m}$ and the $1320 \mathrm{~m}$ height levels are below cloud base.

The observed temporal occurrence frequencies correspond to a spatial occurrence frequency of around $1.0 \mathrm{~km}^{-1}$ or roughly 1.5 per unit length $z_{\mathrm{i}}$ when assuming a horizontal wind speed of $4.2 \mathrm{~m} / \mathrm{s}$ throughout the ABL according to the GDAS data for grid point Leipzig on 5 April. 50\% and 30\% of the time series (09:49-16:45 LT) is covered by downward and upward motions, respectively, for almost all analyzed height levels, except for $1095 \mathrm{~m}$ (45\% downward motion, $40 \%$ upward motion). In $15-30 \%$ of the time the observations are undefined and indicate environmental air according 


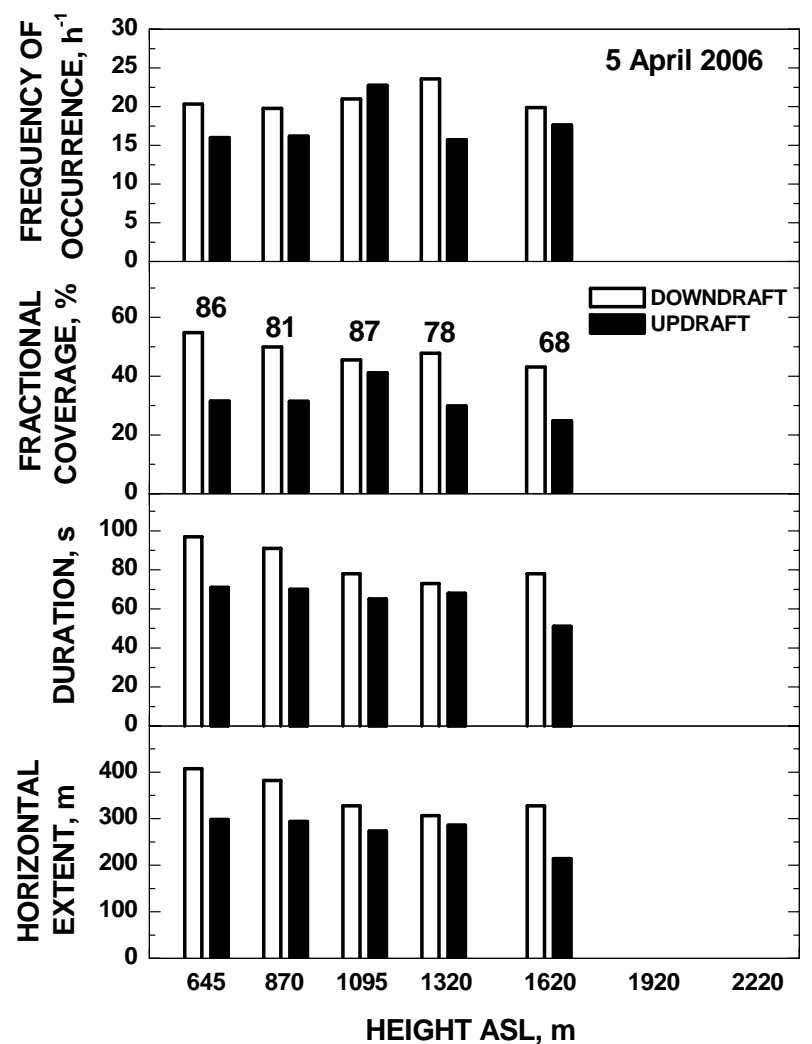

Fig. 6. Mean frequency of occurrence, fractional coverage of up and downdrafts (defined by Eq. (1) and Eq. (2)), mean occurrence duration of the up- and downdrafts, and corresponding mean horizontal extent according to mean horizontal wind speed of $4.2 \mathrm{~m} / \mathrm{s}$. Statistics are separately shown for updrafts (black columns) and downdrafts (white columns) for heights a.s.l. of 645, 870, 1095, 1320, and $1620 \mathrm{~m}$ and for time periods during which vertical velocities could continuously be measured within the entire observational period from 09:49 and 16:45 LT (07:49-14:45 UTC) on 5 April 2006. The total temporal coverage with both updrafts and downdrafts is given as number (in \%) for the different investigated height levels (see fractional coverage plot). About $15-30 \%$ of the time environmental air prevailed, i.e, the draft periods were $<20 \mathrm{~s}$ and/or $-0.1 \mathrm{~m} / \mathrm{s}<w<+0.1 \mathrm{~m} / \mathrm{s}$

to Eqs. (1) and (2), i.e, velocities are $-0.1 \mathrm{~m} / \mathrm{s}<w<+$ $0.1 \mathrm{~m} / \mathrm{s}$ or the period with negative or positive vertical velocity is $<20 \mathrm{~s}$. The mean occurrence duration of the counted updrafts is $50-70 \mathrm{~s}$, which corresponds to a mean horizontal extent of $200-300 \mathrm{~m}$ for horizontal wind speeds around $4 \mathrm{~m} / \mathrm{s}$. Downdrafts occur, on average, for about 70-100 s which translates to $300-400 \mathrm{~m}$ in horizontal extent on that day.

Figures 7 and 8 show the updraft and downdraft characteristics for the other two cases. On 5 May 2006, strong convective motions and a textbook-like development of a cloud-free boundary layer is observed (see Fig. 1). Updraft and downdraft occurrence frequencies are in the range of $16-21 \mathrm{~h}^{-1}$

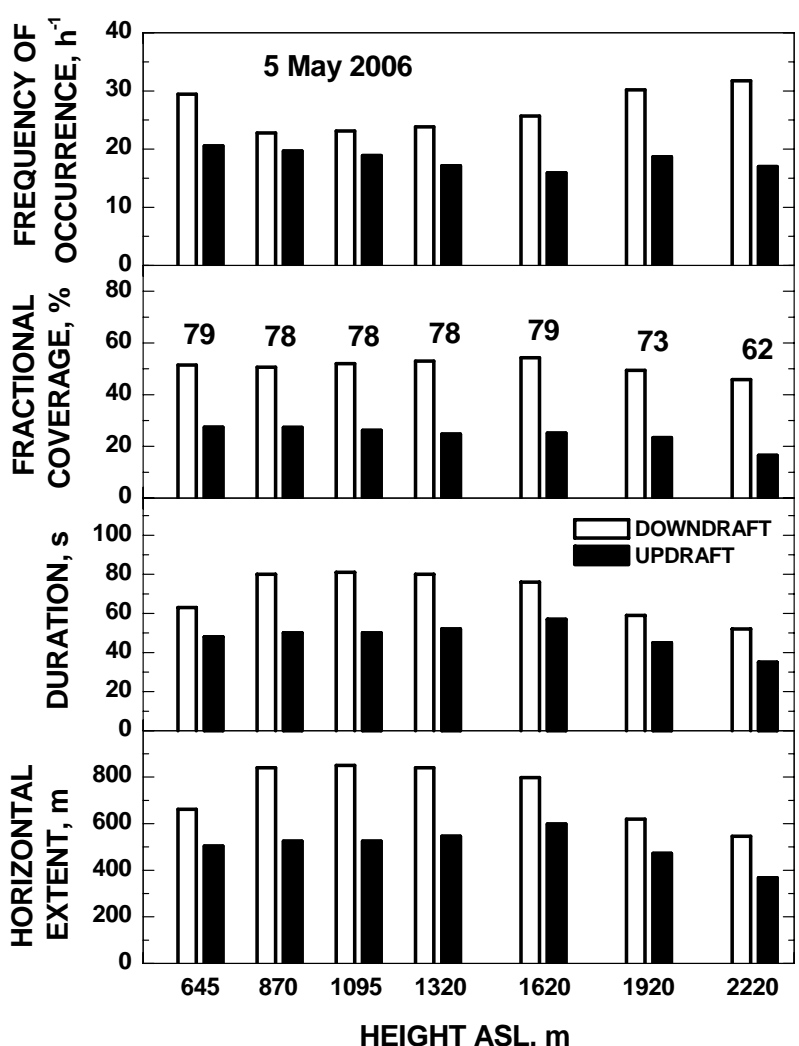

Fig. 7. Same as Fig. 6, except for 5 May 2006, 09:15-18:14 LT (07:15-16:14 UTC).

and $22-32 \mathrm{~h}^{-1}$, respectively. On this clear day, in about $50 \%$ and only $18-27 \%$ of the time downdrafts and updrafts occur, respectively. About $20-30 \%$ of the time is covered with weak upward and downdraft motions (environmental air).

Schumann and Moeng (1991) performed simulations for a cloud-free boundary layer and horizontal wind speeds of $10 \mathrm{~m} / \mathrm{s}$ (similar to the conditions on 5 May 2006). Turbulence was mainly driven by buoyancy with small contributions from shear. $w_{*}$ and $z_{i}$ were $2.0 \mathrm{~m} / \mathrm{s}$ and $1030 \mathrm{~m}$ in their modelling effort, respectively. As a main result, the area fraction of updrafts was $40-45 \%$ and $50-55 \%$ for the downdrafts in the mixing layer $\left(z / z_{i}\right.$ from $\left.0.3-0.7\right)$. They counted all areas with positive and negative vertical velocity as updrafts and downdrafts, respectively. The ratio of the simulated downdraft to updraft mean diameter was $1.4-1.5$ in the mixed layer from $0.3-0.7$ in terms of $z / z_{i}$ and thus in good agreement with our observations. This ratio mostly ranges from 1.2-1.5 in the central part of the convective ABL on 5 April and 5 May. The simulated frequency of occurrence was of the order of 1-1.5 per unit length $z_{i}$ in the mixed layer $\left(z / z_{i}\right.$ from $\left.0.3-0.7\right)$ and thus in the same range of values as observed on 5 April and 5 May 2006.

The much larger mean horizontal extent of the drafts on 5 May (500-600 m updraft mean, 600-900 m downdraft mean 


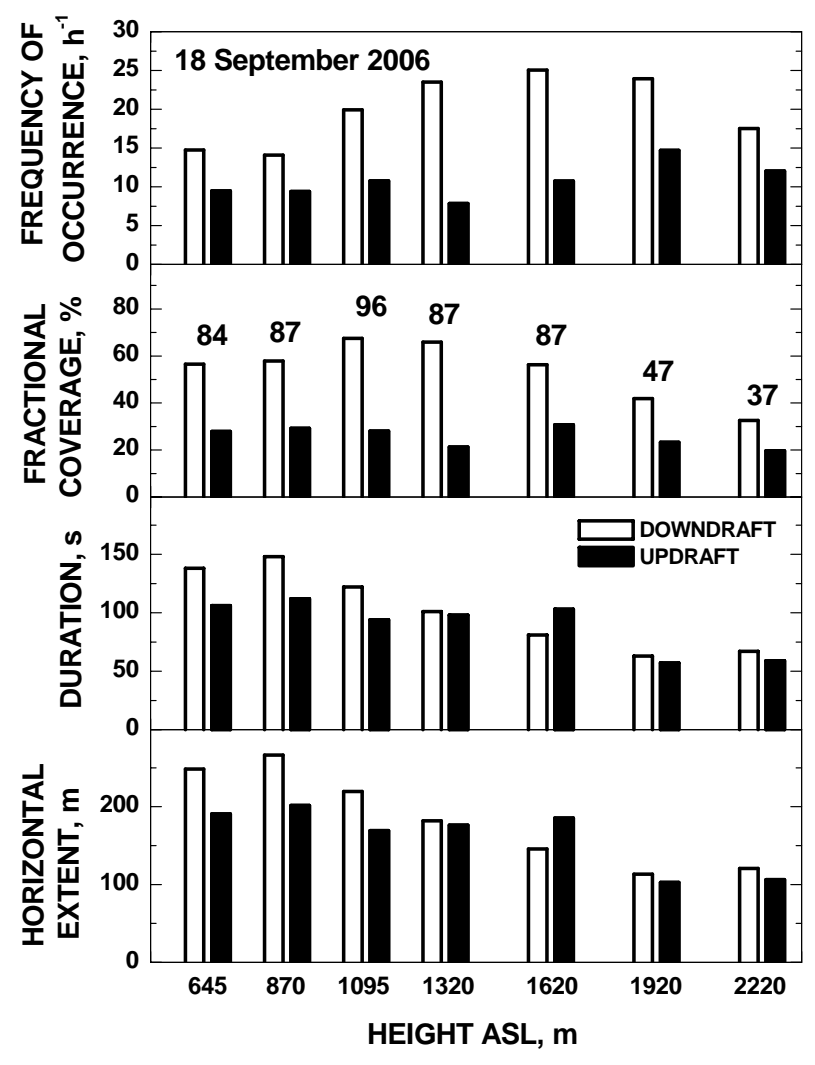

Fig. 8. Same as Fig. 6, except for 18 September 2006, 1020-1905 (08:20-17:05 UTC).

extent) compared to the values for 5 April and for 18 September shown in Fig. 8 is related to the fact that only currents that last for longer than $20 \mathrm{~s}$ are counted and thus considered in the statistics. At high horizontal wind speeds around $10.5 \mathrm{~m} / \mathrm{s}$ only drafts with horizontal extents $>210 \mathrm{~m}$ (cutoff size) are counted, whereas on 5 April $(4.2 \mathrm{~m} / \mathrm{s})$ and 18 September $(1.8 \mathrm{~m} / \mathrm{s})$ the cutoff size is $84 \mathrm{~m}$ and $36 \mathrm{~m}$, respectively, and consequently the average values of the updraft and downdraft sizes are much lower on 5 April and even lower on 18 September (100-250 m).

The ratio of downdraft-to-updraft fractional coverage is much higher on the cloud-free 5 May than on the 5 April. The same roughly holds for the downdraft-to-updraft duration ratio or horizontal extent ratio. This behavior is caused by the occurrence of many long lasting updrafts below the cloud bases on 5 April. On the other hand, the downdraft characteristics remains almost unaffected by cloud formation and is thus similar on 5 April and 5 May.

On 18 September 2006, strong upward and downward motion occur before 16:30 LT. After 16:15 LT waves appear in the aerosol layer above $1600 \mathrm{~m}$ height a.s.l. An airmass change obviously occurs around 16:15 LT. The wave activity at higher altitudes is indicative for comparably stable conditions which may explain the rather low number of updrafts.
Downdrafts are a factor of 3 more frequent around $1320 \mathrm{~m}$ height than updrafts in Fig. 8. The increasing number of updrafts with maximum around $1620-1920 \mathrm{~m}$ is related to the systematic up and downward motions associated with the wave activity above $1620 \mathrm{~m}$ height a.s.l. after 16:00 LT.

At this stage of data analysis, a significant difference between the moist (5 April) and dry ABL development (5 May, 18 September) is not found, except the enhanced updraft frequency at cloud levels on 5 April. In the further analysis of the observations, we consider the different horizontal wind speeds of about 2, 4, and $10 \mathrm{~m} / \mathrm{s}$ at the different days. Furthermore to better compare the findings of the three days we consider only the central time period of the ABL evolution from 12:00-17:00 LT (until 16:45 LT on 5 April) and the height levels of 645, 870, and $1170 \mathrm{~m}$ (see Fig. 1) which are at least on 5 April and 5 May always fully in the ABL (and mostly in the subcloud layer on 5 April). On 18 September, the ABL top reaches the 870 and $1170 \mathrm{~m}$ height level not before 13:15 and 13:45 LT, respectively. Therefore, we consider only the data sets for the lowest level of $645 \mathrm{~m}$. The findings are summarized in Table 1.

During almost $1.5 \mathrm{~h} \mathrm{(30-34 \% )}$ and more than $2.5 \mathrm{~h}(52-$ $57 \%$ ) of the $5 \mathrm{~h}$ periods updrafts and downdrafts lasting for longer than $20 \mathrm{~s}$ and showing vertical velocities $<-0.1 \mathrm{~m} / \mathrm{s}$ or $>0.1 \mathrm{~m} / \mathrm{s}$ are observed in the fully developed convective boundary layer disregarding the occurrence of fair-weather cumuli, the strength of horizontal wind speed, and ABL height $z_{i}$. The mean frequency of occurrence of significant updrafts is also remarkably equal at all three days with values of 1.2-1.7 per unit length $z_{i}$ during the central time period from 12:00-17:00 LT.

To eliminate the cutoff effect (caused by the different horizontal wind speeds), we assume that on 18 September, the day with lowest horizontal wind speed of $1.8 \mathrm{~m} / \mathrm{s}$, all relevant updrafts and downdrafts are counted, and that the frequency distributions of updraft and downdraft sizes found on 18 September holds for the other two days, too. The frequency distribution of updrafts and downdrafts for all three days are presented in Fig. 9. All distributions show an exponential decrease of the relative occurrence frequency of drafts with draft size. Keeping this observed exponential decrease into consideration, $25-30 \%$ of the updrafts and downdrafts, i.e., all drafts with sizes from $36-84 \mathrm{~m}$, remained undetected on 5 April. For the 5 May, we yield that $45-50 \%$ of the downdrafts (drafts with horizontal extents from 36-210 m) remained undetected. If we consider these missing drafts in the statistics, the mean horizontal extent is about $235 \mathrm{~m}$ (5 April) and $420 \mathrm{~m}$ (5 May) for the updrafts, and $300 \mathrm{~m}$ (5 April) and $570 \mathrm{~m}$ (5 May) for the downdrafts. These values (estimates for an assumed minimum draft extent of $36 \mathrm{~m}$ ) are included in Table 1.

As shown in Figs. 10 and 11, larger updrafts and downdrafts show larger vertical velocities, so that also the mean values of draft vertical velocity increase with increasing observational cutoff size. Mean vertical velocities are $0.66 \mathrm{~m} / \mathrm{s}$ 
Table 1. Summary of updraft and downdraft properties for the three cases discussed. Mean values (and partly standard deviations) are presented for the time period from 12:00-17:00 LT on 5 May and 18 September and from 12:00-16:45 LT on 5 April, and by considering the vertical velocity times series for the height levels of 645,870 , and $1170 \mathrm{~m}$ on 5 April and 5 May. Occurrence parameters for the 18 September are computed from the data sampled at the $645 \mathrm{~m}$ height level only. The integrated occurrence time (fractional coverage in percent) is related to the total $4.75 \mathrm{~h}$ and $5 \mathrm{~h}$ observation periods, occurrence rate is calculated from the number of detected drafts during the total period of 4.75-5 h. Mean horizontal extent is simply obtained by the mean draft occurrence period (in seconds) multiplied by the estimated wind speed given in the table. Minimum horizontal size (cutoff size) of counted drafts is indicated in the table $(84 \mathrm{~m}, 210 \mathrm{~m}, 36 \mathrm{~m})$. Estimates of draft mean size and velocity for a cutoff size of $36 \mathrm{~m}$ are given in addition.

\begin{tabular}{|c|c|c|c|}
\hline & 5 April 2006 & 5 May 2006 & 18 September 2006 \\
\hline Clouds & Fair-weather cumuli & Cloud-free & Few cumuli \\
\hline Wind speed ( $z=0.5-1 \mathrm{~km}$, estimate $)$ & $4.2 \mathrm{~m} / \mathrm{s}$ & $10.5 \mathrm{~m} / \mathrm{s}$ & $1.8 \mathrm{~m} / \mathrm{s}$ \\
\hline ABL height $z_{i}$ (above ground) & $1.45 \mathrm{~km}$ & $2.3 \mathrm{~km}$ & $1.3 \mathrm{~km}$ \\
\hline Convective velocity scale $w_{*}$ & $1.5 \mathrm{~m} / \mathrm{s}$ & $1.75 \mathrm{~m} / \mathrm{s}$ & $1.3 \mathrm{~m} / \mathrm{s}$ \\
\hline Updrafts (cutoff size) & $84 \mathrm{~m}$ & $210 \mathrm{~m}$ & $36 \mathrm{~m}$ \\
\hline Occurrence (fractional coverage) & $34 \%$ & $31 \%$ & $30 \%$ \\
\hline Occurrence rate & $0.30 \min ^{-1}$ & $0.32 \min ^{-1}$ & $0.14 \min ^{-1}$ \\
\hline Spatial occurrence & $1.2 \mathrm{~km}^{-1}$ & $0.5 \mathrm{~km}^{-1}$ & $1.3 \mathrm{~km}^{-1}$ \\
\hline Spatial occurrence & $1.7 z_{i}^{-1}$ & $1.2 z_{i}^{-1}$ & $1.7 z_{i}^{-1}$ \\
\hline Mean horizontal extent $d_{\text {up }}$ & $289 \pm 314 \mathrm{~m}$ & $622 \pm 725 \mathrm{~m}$ & $203 \pm 278 \mathrm{~m}$ \\
\hline Mean vertical velocity $w_{\text {up }}$ & $0.76 \pm 0.59 \mathrm{~m} / \mathrm{s}$ & $0.91 \pm 0.71 \mathrm{~m} / \mathrm{s}$ & $0.55 \pm 0.51 \mathrm{~m} / \mathrm{s}$ \\
\hline$d_{\text {up }}($ cutoff size $=36 \mathrm{~m})$ & $235 \mathrm{~m}$ & $417 \mathrm{~m}$ & $203 \mathrm{~m}$ \\
\hline$d_{\text {up }}($ cutoff size $=36 \mathrm{~m})$ & $0.16 z_{i}$ & $0.18 z_{i}$ & $0.16 z_{\mathrm{i}}$ \\
\hline$w_{\text {up }}($ cutoff size $=36 \mathrm{~m})$ & $0.66 \mathrm{~m} / \mathrm{s}$ & $0.71 \mathrm{~m} / \mathrm{s}$ & $0.55 \mathrm{~m} / \mathrm{s}$ \\
\hline$w_{\text {up }}($ cutoff size $=36 \mathrm{~m})$ & $0.44 w_{*}$ & $0.41 w_{*}$ & $0.42 w_{*}$ \\
\hline Downdrafts (cutoff size) & $84 \mathrm{~m}$ & $210 \mathrm{~m}$ & $36 \mathrm{~m}$ \\
\hline Occurrence (fractional coverage) & $53 \%$ & $54 \%$ & $57 \%$ \\
\hline Occurrence rate & $0.35 \min ^{-1}$ & $0.40 \min ^{-1}$ & $0.23 \mathrm{~min}^{-1}$ \\
\hline Mean horizontal extent $d_{\mathrm{do}}$ & $374 \pm 329 \mathrm{~m}$ & $848 \pm 890 \mathrm{~m}$ & $295 \pm 492 \mathrm{~m}$ \\
\hline Mean vertical velocity $w_{\text {do }}$ & $-0.65 \pm 0.49 \mathrm{~m} / \mathrm{s}$ & $-0.89 \pm 0.72 \mathrm{~m} / \mathrm{s}$ & $-0.43 \pm 0.35 \mathrm{~m} / \mathrm{s}$ \\
\hline$d_{\mathrm{do}}($ cutoff size $=36 \mathrm{~m})$ & $304 \mathrm{~m}$ & $569 \mathrm{~m}$ & $295 \mathrm{~m}$ \\
\hline$w_{\text {do }}($ cutoff size $=36 \mathrm{~m})$ & $-0.58 \mathrm{~m} / \mathrm{s}$ & $-0.71 \mathrm{~m} / \mathrm{s}$ & $-0.43 \mathrm{~m} / \mathrm{s}$ \\
\hline
\end{tabular}

and $-0.58 \mathrm{~m} / \mathrm{s}$ (5 April) and $0.71 \mathrm{~m} / \mathrm{s}$ and $-0.71 \mathrm{~m} / \mathrm{s}$ (5 May) for updrafts and downdrafts, respectively, when the missing updrafts and downdrafts with sizes down to $36 \mathrm{~m}$ are taken into account. If we finally express the corrected values as functions of the boundary-layer height $z_{i}$ and the convective velocity scale $w_{*}$ given in the table, we end up with values of $0.16 z_{i}-0.18 z_{i}$ for mean updraft size for all three days, and for the mean updraft velocity with values of $0.4 w_{*}-0.45 w_{*}$ for all three days disregarding the occurrence of cumulus clouds. A significant difference of the ABL characteristics on 5 May and 18 September and in the subcloud layer on 5 April is thus not observed.

The values in Table 1 are in good agreement with observations of Lenschow and Stephens (1980). They used humidity fluctuations (exceeding a certain threshold value for horizontal extents $\geq 25 \mathrm{~m}$ ) over an oceanic site to identify updrafts and downdrafts and found values from $0.08 z_{i}-0.15 z_{i}$ for the updraft mean size in the height range from $z / z_{i}=0.2$ to 0.8 . They obtained values of $0.4 \pm 0.1 w_{*}$ as a mean vertical velocity in updrafts.
Young (1988b) analyzed low-pass filtered vertical velocity time series measured during 58 flight legs, each approximately $35 \mathrm{~km}$ long and evenly distributed from height level $0.1 z_{i}$ to $1.3 z_{i}$, and counted any event larger than $40 \mathrm{~m}$ in size showing positive vertical velocity as updraft, and the residual data segments (periods) as downdrafts. The observations were performed in the framework of the September 1978 Phoenix Convective Boundary Layer Experiment at the Boulder Atmospheric Observatory. The arithmetic mean updraft width for the individual flight legs ranged from $0.15 z_{i}$ to $0.35 z_{i}$. The arithmetic mean value of the updraft mean vertical velocity was $0.3 w_{*}-0.7 w_{*}$ for the range $z / z_{i}$ from $0.3-0.7$. For downdrafts the respective vertical velocities accumulated between $-0.3 w_{*}$ and $-0.6 w_{*}$.

\subsection{Draft mean velocity versus draft size}

To further investigate potential differences between cloudfree and cloud-topped mixing layers, the dependence of the draft vertical velocity on the size of the updrafts and downdrafts is illuminated. The potential impact of fair-weather cumuli on this relationship is presented in Figs. 10 and 11. 


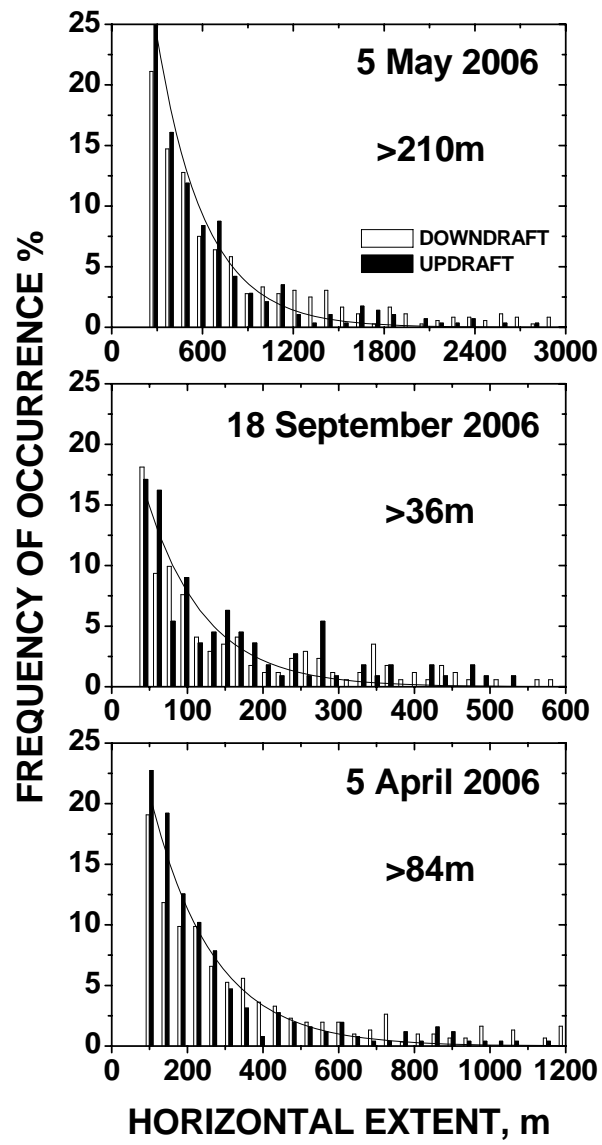

Fig. 9. Frequency of occurrence of updraft (black) and downdraft (white) horizontal extents (observed occurrence duration $>20 \mathrm{~s}$ times horizontal wind speed) for $10 \mathrm{~s}$ occurrence duration intervals (20-30 s, 30-40 s, etc.). The statistical results consider all updraft and downdraft events observed at the 645,870 , and $1170 \mathrm{~m}$ height levels on 5 April, 12:00-16:45 LT, and on 5 May and 18 September, 12:00-17:00 LT. Curves (exponential functions) are fitted to the observed updrafts and downdrafts. Fit parameters are given in Table 2.

Table 2. Fit parameters ( \pm standard deviation) describing the exponential curves in Fig. 9. The function is $N_{\mathrm{d}}=A \exp (-d / B)$ with the number of updrafts or downdrafts $N_{\mathrm{d}}$ and horizontal extent $d$.

\begin{tabular}{lll}
\hline & A & B \\
\hline Updrafts, downdrafts, 5 May & $61.24 \pm 4.54$ & $318.42 \pm 17.43$ \\
Updrafts, downdrafts, 18 Sep. & $28.04 \pm 2.36$ & $78.15 \pm 6.08$ \\
Updrafts, downdrafts, 5 April & $38.34 \pm 1.93$ & $164.14 \pm 7.29$ \\
\hline
\end{tabular}

The mean velocity shown in the figures describe the mean value of all updraft and downdraft vertical velocities found for a given size class (horizontal extent interval). The individual values of updraft or downdraft vertical velocity in this averaging are mean values averaged over the horizontal cross section of the drafts.

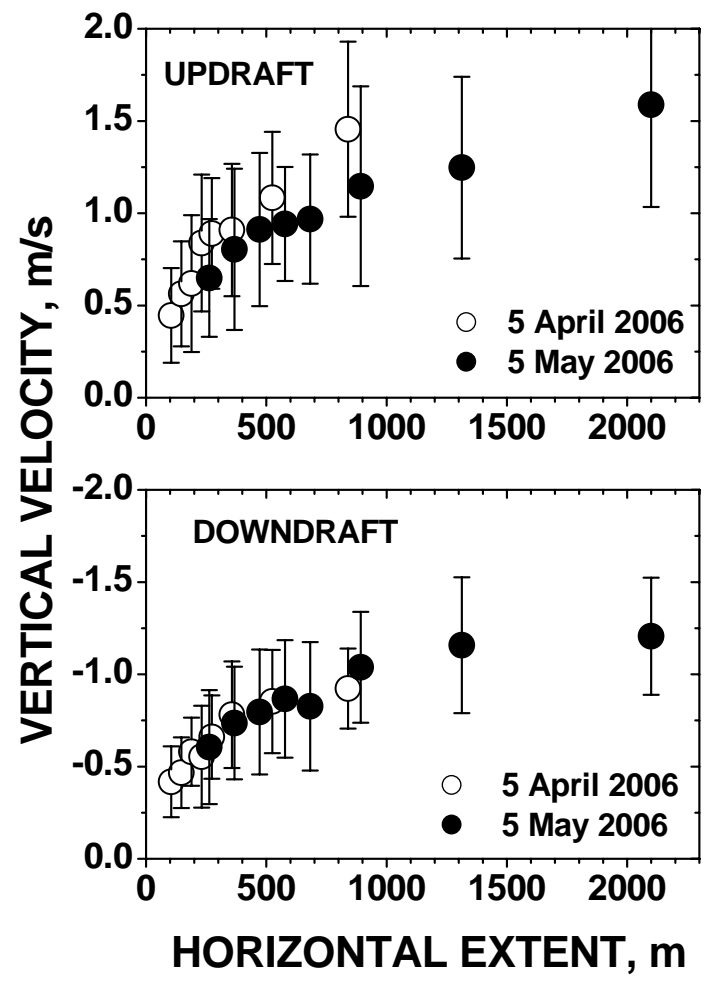

Fig. 10. Updraft mean (top) and downdraft mean vertical velocity (bottom) as a function of draft horizontal extent (temporal length of the observed updraft and downdraft periods times horizontal wind speed). Average values (symbols) and standard deviations (vertical bars) are presented for eight occurrence duration intervals (20$30 \mathrm{~s}, 30-40 \mathrm{~s}, 40-50 \mathrm{~s}, 50-60 \mathrm{~s}, 60-70 \mathrm{~s}, 70-100 \mathrm{~s}, 100-150 \mathrm{~s}$, and 150-250s). For each of the four scenarios (5 April and 5 May, updrafts and downdrafts) 30-90 events were available for intervals from $20-30 \mathrm{~s}$ and $40-50 \mathrm{~s}$, and $20-50$ events for the larger occurrence time intervals. The statistical results consider all updraft and downdraft events observed at the 645, 870, and $1170 \mathrm{~m}$ height levels on 5 April, 12:00-16:45 LT and on 5 May, 12:00-17:00 LT.

We concentrate on the almost textbook-like convective days (5 April, 5 May). All updraft and downdraft events measured at the height levels of 645,870 and $1170 \mathrm{~m}$ during the 12:00-16:45 LT (5 April) and 12:00-17:00 LT time period (5 May) are considered in Fig. 10. Now a clear tendency is observed. On average, the updraft mean velocity increases from about $0.5 \mathrm{~m} / \mathrm{s}$ for small drafts (small with respect to their horizontal extent) to $1.5 \mathrm{~m} / \mathrm{s}$ for large thermals with horizontal extents of $600-1000 \mathrm{~m}$ (150-250 s duration interval in Fig. 10). The mean updraft velocities are at all larger for the different size classes on 5 April. The velocityversus-size characteristics for downdrafts is very similar on the two days. Maximum downdraft velocities accumulate from $0.8-1.2 \mathrm{~m} / \mathrm{s}$ for large drafts on both days. 


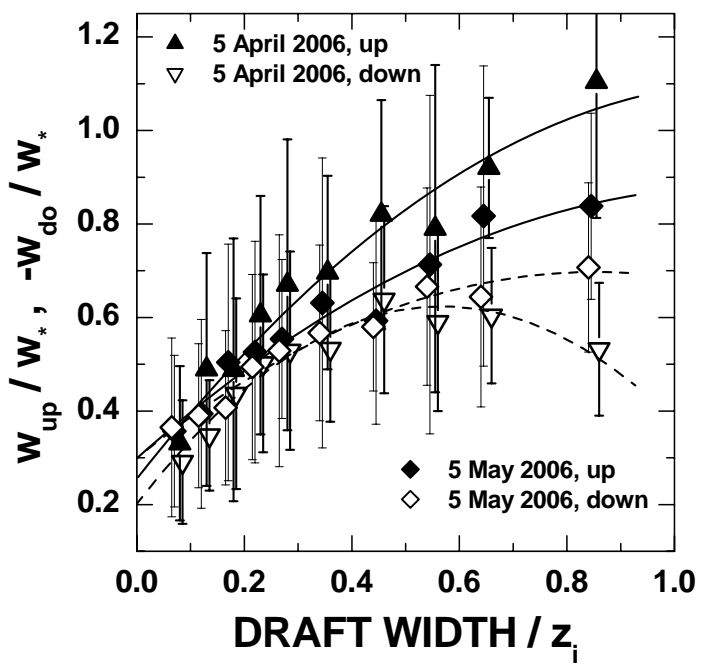

Fig. 11. Updraft and (negative) downdraft vertival velocity $w_{\text {up }}$ and $-w_{\text {do }}$ normalized to the convection velocity scale $w_{*}$ versus draft width normalized to the ABL top height $z_{i}$. Curves (polynomial functions) are fitted to the observed data. Fit parameters are given in Table 3.

Table 3. Fit parameters ( \pm standard deviation) describing the line curves in Fig. 11. The function is $w_{\mathrm{D}} / w_{*}=A+B 1\left(d / z_{i}\right)+$ $B 2\left(d / z_{i}\right)^{2}$ with $w_{\mathrm{D}}=w_{\text {up }}$ or $w_{\mathrm{D}}=-w_{\mathrm{do}}$.

\begin{tabular}{llll}
\hline & A & B1 & B2 \\
\hline Updrafts, 5 April & $0.30 \pm 0.053$ & $1.27 \pm 0.28$ & $-0.43 \pm 0.31$ \\
Updrafts, 5 May & $0.30 \pm 0.041$ & $1.02 \pm 0.22$ & $-0.45 \pm 0.24$ \\
Downdraft, 5 April & $0.20 \pm 0.028$ & $1.49 \pm 0.15$ & $-1.31 \pm 0.16$ \\
Downdraft, 5 May & $0.29 \pm 0.024$ & $0.94 \pm 0.13$ & $-0.54 \pm 0.14$
\end{tabular}

In Fig. 11, the influence of the boundary-layer depth $z_{i}$ on the relationship between velocity and size is removed by dividing the draft width $d$ by $z_{i} . d$ and $z_{i}$ were measured simultaneously with Doppler lidar and small aerosol lidar, respectively. Furthermore the velocities are normalized by using the convective velocity scale $w_{*}$. The time series of $w_{*}$ obtained from 1-h and 2-h $\sigma_{w}^{2}(z)$ profiles as shown in Fig. 3 did not show any trend over the day so that we simply used $w_{*}$ from Table 1 for this normalization.

The dependence of the normalized downdraft mean velocity on $d / z_{i}$ is almost the same on 5 April and 5 May for normalized downdraft sizes $<0.6$, but then decreases with draft size on the day with cloud development (5 April). The curves describing the dependence of the updraft mean vertical velocity on draft size show a steeper slope than the respective downdraft curves. The strongest velocity increase with increasing updraft extent is found on 5 April. The mean values are at all larger on 5 April than on 5 May. The vertical velocity is, on average, about $20 \%$ stronger in the large thermals on the day with cloud formation.

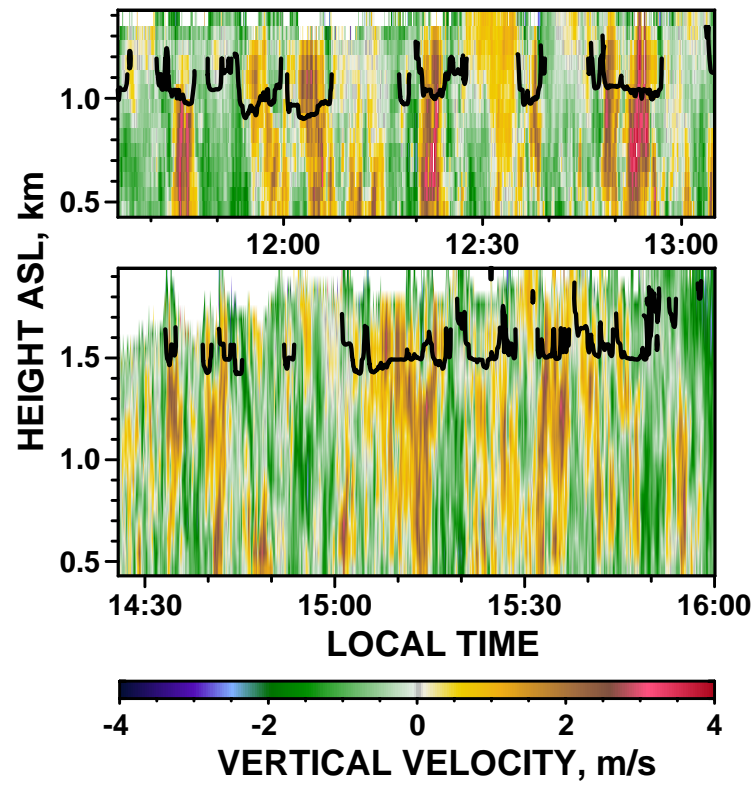

Fig. 12. Updrafts below cumulus clouds observed on 5 April 2006, in the early stage of the ABL evolution (top, 11:30-13:00 LT) and close to its end (bottom, 14:30-16:00 LT). Cloud base heights are indicated by black lines. The horizontal extent of the strong updrafts around $11: 45,12: 22$, and $12: 53 \mathrm{LT}$ is $800-1000 \mathrm{~m}$, and the updraft mean velocity ranges from $1.6-2.4 \mathrm{~m} / \mathrm{s}$. Peak velocity values in the updrafts frequently exceed $3 \mathrm{~m} / \mathrm{s}$, sometimes $4 \mathrm{~m} / \mathrm{s}$. In the afternoon less coherent updraft structures are observed below the clouds.

Figure 12 corroborates the hypothesis that there is a link between the development of stronger updrafts showing high velocities and the formation of fair-weather cumuli. Two periods already shown in Fig. 1 are presented. Vigorous updrafts with occurrence lengths of 180-220 s, which corresponds to horizontal extents of $800-1000 \mathrm{~m}$, and thermal mean velocities of up to $1.5-3 \mathrm{~m} / \mathrm{s}$ are visible below the clouds. In the cores of these updrafts vertical winds are sometimes about a factor of two higher than the plume mean vertical velocity. These clouds already develop during the morning hours when the boundary-layer height is about $1100 \mathrm{~m}$. In the afternoon, cloud base height is $500 \mathrm{~m}$ higher (around $1400 \mathrm{~m}$ height a.s.l.) and the boundary-layer height is close to $1700-1800 \mathrm{~m}$. The updrafts below the cloud base are still pronounced (occurrence duration frequently $>100 \mathrm{~s}$ ) but less intense (updraft mean velocities of $1-2 \mathrm{~m} / \mathrm{s}$ ).

Figure 12 is consistent with the conceptual models and respective parameterizations developed during the last 10 years to describe the vertical exchange in the moist, cumulustopped ABL (Jakob and Siebesma, 2003; Soares et al., 2004; Angevine, 2005). The models distinguish between a subcloud layer and a cloud layer. The basic idea of these models is that only the most energetic updrafts form clouds, and that all of the transport through the cloud base is then provided by 
these strong updrafts. In the scheme of Jakob and Siebesma (2003), the updraft vertical velocity plays a key role in the identification of the updrafts that are able to form clouds. Only updrafts with the highest positive vertical velocities form clouds in their approach. Some of the developed models were able to reproduce the cumulus onset time as observed, e.g., by Wilde et al. (1985), suggesting a direct connection between the cumulus onset and the first strong and large thermals that reach the condensation level.

Finally it is worthwhile to mention that Kollias et al. (2001) analyzed radar observations of the updraft and downdraft behavior in fair-weather cumuli and stated that even small cumuli with horizontal extents of the order of $1000 \mathrm{~m}$ (as the smaller ones in Fig. 12) should be considered as convective complexes rather than simple growing elements that later decay into passive clouds. The two cumuli studied by Kollias et al. (2001) consisted of an updraft core of $400 \mathrm{~m}$ width surrounded by narrow downdrafts ( $100 \mathrm{~m}$ width). In these clouds with a vertical depth of about $700 \mathrm{~m}$ updraft velocities of about $5.5 \mathrm{~m} / \mathrm{s}$ were observed. The updraft core structure suggested that the cumulus clouds were composed of successive bubbles that emerge from the subcloud layer. Figure 12 (afternoon period) is in accordance with this explanation. The interaction of the turbulent mixing processes in $\mathrm{ABL}$ and the evolution of convective clouds in the upper part of the ABL are closely coupled. Large thermals initiate the development of cumuli and, in the subsequent step, the freshly formed clouds reinforce the thermals (chimney effect) and may combine smaller updrafts to larger ones, which in turn is of advantage to stimulate deeper convection of the developing cloud towers.

\section{Conclusions}

In summary, a first comprehensive Doppler lidar study on the updraft and downdraft characteristics in the boundary layer has been presented. As a new aspect, we contrasted the evolution of the ABL at cloud-free and cloudy conditions. The high-quality data sets of vertical-wind observations enabled us to analyze the relationship between the horizontal extent of the updraft and downdrafts and their mean vertical velocity.

Three cases of the diurnal evolution of the atmospheric boundary layer over the flat rural/urban Leipzig area, Germany, were studied. The counted updraft events covered $30-34 \%$, the downdrafts $53-57 \%$ of the velocity time series during the main convective periods around noon and the early afternoon. During the day with fair-weather cumuli, the frequency of occurrence of downdrafts and updrafts was enhanced by a factor of about 1.5 at height levels close to cloud base. The mean horizontal extent of the updrafts ranged from 200-420 $\mathrm{m}$ or from $0.16 z_{i}-0.18 z_{i}$ when all coherent features with horizontal extents of $>36 \mathrm{~m}$ were considered in the statistics. Downdrafts were found to be, on average, a factor of 1.3-1.5 larger than updrafts regarding the horizontal extent. The average value of the updraft vertical velocities ranged from $0.5-0.7 \mathrm{~m} / \mathrm{s}$ or $0.4 w_{*}-0.45 w_{*}$ at all three stations at all three days disregarding the occurrence of clouds. All these values agree well with the literature and indicated the high quality of our Doppler lidar observations.

The relationship between the horizontal extent of the updrafts and downdrafts and their mean vertical velocity was highlighted. This analysis revealed a pronounced increase of the average vertical velocity of the updrafts from values around $0.4-0.5 \mathrm{~m} / \mathrm{s}$ for small thermals $\left(100-200 \mathrm{~m}, d / z_{i}\right.$ of $0.1-0.15$ ) to about $1.5 \mathrm{~m} / \mathrm{s}$ for large thermals ( $>600 \mathrm{~m}, d / z_{i}$ from 0.6-0.8) in the case with fair-weather cumuli.

As an outlook, more contrasting (cloudy versus cloudfree) studies are necessary to corroborate our findings and to support atmospheric modeling. Especially more cases with cumulus congestus, i.e., clouds which are able to deeply penetrate into the free troposphere, must be monitored and analyzed. Meanwhile, several campaigns have been conducted with our Doppler lidar. Besides the half-year AVEC 2006 campaign, we performed intensive field observations in the tropics (Cape Verde in 2008) and in southwestern Germany in orographically complex terrain in the summer of 2007. Future Doppler and aerosol/cloud/polarization lidar studies at Leipzig will focus on fair-weather cloud-topped boundary layers, aerosol-cloud interactions, and the role of turbulence in this context.

Acknowledgements. We thank the reviewers for their fruitful comments. We thank Gerald Spindler and Achim Grüner, Leibniz Institute for Tropospheric Research, for providing the meteorological observations at the Melpitz field site.

Edited by: B. Stevens

\section{References}

Angevine, W. M.: An integrated turbulence scheme for boundary layers with shallow cumulus applied to pollutant transports, J. Appl. Meteorol., 44, 1436-1452, 2005.

Ansmann, A., Tesche, M., Knippertz, P., Bierwirth, E., Althausen, D., Müller, D., and Schulz, O.: Vertical profiling of convective dust plumes in southern Morocco during SAMUM, Tellus B, 61, 340-353, 2009.

Baars, H., Ansmann, A., Engelmann, R., and Althausen, D.: Continuous monitoring of the boundary-layer top with lidar, Atmos. Chem. Phys., 8, 7281-7296, doi:10.5194/acp-8-7281-2008, 2008.

Bösenberg, J. and Linné, H.: Laser remote sensing of the planetary boundary layer, Meteorol. Z., 11, 233-240, 2002.

Cotton, W. R., Alexander, G. D., Hertenstein, R., Walko, R. L., McAnelly, R. L., and Nicholls, M.: Cloud venting - a review and some new global annual estimates, Earth-Sci. Rev., 39, 169-206, 1995.

Dabas, A. M., Dobrinski, P., and Flamant, P. H.: Chirp-induced bias in velocity measurements by a coherent Doppler $\mathrm{CO}_{2}$ lidar, J. Atmos. Ocean. Tech., 15, 407-415, 1998. 
Drobinski, P., Carlotti, P., Newsom, R. K., Banta, R. M., Foster, R. C., and Redelsperger, J.-L.: The structure of the near-neutral atmospheric surface layer, J. Atmos. Sci., 61, 699-714, 2004.

Durand, P., Thoumieux, F., and Lambert, D.: Turbulent lengthscales in the marine atmospheric mixed layer, Q. J. Roy. Meteorol. Soc., 126, 1889-1912, 2000.

Engelmann, R.: Aerosol vertical exchange in the convective planetary boundary layer, Dissertation, University of Leipzig, Germany, 2009.

Engelmann, R., Wandinger, U., Ansmann, A., Müller, D., Žeromskis, E., Althausen, D., and Wehner, B.: Lidar observations of the vertical aerosol flux in the planetary boundary layer, J. Atmos. Ocean. Tech., 25, 1296-1306, 2008.

Frehlich, R.: Estimation of velocity error for Doppler lidar measurements, J. Atmos. Ocean. Tech., 18, 1628-1639, 2001.

Fruntke, J.: Charakterisierung der Grenzschicht anhand von Vertikalwindmessungen mit einem Doppler-Lidar, (Characterization of the boundary layer by means of vertical wind measurements with Doppler lidar), Diploma thesis, University of Leipzig, Germany, 2009.

Gibert, F., Cuesta, J., Yano, J.-I., Arnault, N., and Flamant, P. H.: On the correlation between convective plume updrafts and downdrafts, lidar reflectivity and depolarization ratio, Bound.-Lay. Meteorol., 125, 553-573, 2007.

Godowitch, J. M.: Characteristics of vertical turbulent velocities in the urban convective boundary layer, Bound.-Lay. Meteorol., 35, 387-407, 1986

Greenhut, G. K. and Khalsa, S. J. S.: Updraft and downdraft events in the atmospheric boundary layer over the equatorial Pacific Ocean, J. Atmos. Sci., 39, 1803-1817, 1982.

Greenhut, G. K. and Khalsa, S. J. S.: Convective elements in the marine atmospheric boundary layer. Part I: conditional sampling studies, J. Clim. Appl. Meteorol., 26, 813-822, 1987.

Grund, C. J., Banta, R. M., George, J. L., Howell, J. N., Post, M. J., Richter, R. A., and Weickmann, A. M.: High-resolution Doppler lidar for boundary layer and cloud research, J. Atmos. Ocean. Tech., 18, 376-393, 2001.

Heus, T., Pols, C. F. J., Jonker, H. J. J., van den Acker, H. E. A., and Lenschow, D. H.: Observational validation of the compensating mass flux through the shell around cumulus clouds, Q. J. Roy. Meteorol. Soc., 135, 101-112, 2009.

Hogan, R. J., Grant, A. L. M., Illingworth, A. J., Pearson, G. N., and O'Connor, E. J.: Vertical velocity variance and skewness in clear and cloud-topped boundary layers as revealed by Doppler lidar, Q. J. Roy. Meteorol. Soc., 135, 635-643, 2009.

Jakob, C. and Siebesma, A. P.: A new subcloud model for mass-flux convection schemes: Influence on triggering, updraft properties, and model climate, Mon. Weather Rev., 131, 2765-2778, 2003.

Khalsa, S. J. S. and Greenhut, G. K.: Conditional sampling of updrafts and downdrafts in the marine atmospheric boundary layer, J. Atmos. Sci., 42, 2550-2562, 1985.

Kollias, P., Albrecht, B. A., Lhermitte, R., and Savtchenko, A.: Radar observations of updrafts, downdrafts, and turbulence in fair-weather cumuli, J. Atmos. Sci., 58, 1750-1766, 2001.

Lenschow, D. H.: Airplane boundary layer structure, J. Appl. Meteorol., 9, 874-884, 1970.

Lenschow, D. H. and Stephens, P. L.: The role of thermals in the convective boundary layer, Bound.-Lay. Meteorol., 19, 509-532, 1980.
Lenschow, D. H. and Stephens, P. L.: Mean vertical velocity and turbulence intensity inside and outside thermals, Atmos. Environ., 16, 61-64, 1982.

Lenschow, D. H., Mann, J., and Kristensen, L.: How long is long enough when measuring fluxes and other turbulence statistics?, J. Atmos. Ocean. Tech., 11, 661-673, 1994.

Lothon, M., Lenschow, D. H., and Mayor, S. D.: Coherence and scale of vertical velocity in the convective boundary layer from Doppler lidar, Bound.-Lay. Meteorol., 35, 387-407, 2006.

Moeng, C.-H. and Rotunno, R.: Vertical-velocity skewness in the buoyancy-driven boundary layer, J. Atmos. Sci., 47, 1149-1162, 1990.

Patton, E. G., Sullivan, P. P., and Moeng, C.-H.: The influence of idealized heterogeneity on wet and dry planetary boundary layers coupled to the land surface, J. Atmos. Sci., 62, 2078-2097, 2005.

Said, F., Canut, G., Durand, P., Lohou, F., and Lothon, M.: Seasonal evolution of boundary-layer turbulence measured by aircraft during the AMMA 2006 Special Observation Period, Q. J. Roy. Meteorol. Soc., 135, 595-617, 2009.

Schumann, U. and Moeng, C.-H.: Plume fluxes in clear and cloudy convective boundary layers, J. Atmos. Sci., 48, 1746-1757, 1991.

Seifert, P., Engelmann, R., Ansmann, A., Wandinger, U., Mattis, I., Althausen, D., and Fruntke, J.: Characterization of specular reflections in mixed-phase and ice clouds based on scanning, polarization, and Raman lidar, in: Reviewed and revised papers presented at the 24th International Laser Radar Conference, 23-28 June 2008, Boulder, Colorado, USA, edited by: Hardesty, M. and Mayor, S., 571-574, NOAA, Boulder, CO, USA, ISBN 9780-615-21489-4, 2008.

Soares, P. M. M., Miranda, P. M. A., Siebesma, A. P., and Teixeira, J.: An eddy-diffusivity/mass-flux parametrization for dry and shallow cumulus convection, Q. J. Roy. Meteorol. Soc., 130, 3365-3383, 2004.

Spindler, G., Teichmann, U., and Sutton, M. A.: Ammonia dry deposition over grassland - micrometeorological flux-gradient measurements and bi-directional flux calculations using an inferential model, Q. J. Roy. Meteorol. Soc., 127, 795-814, 2001.

Stull, R. B.: An Introduction to Boundary Layer Meteorology, Kluwer Academic Publishers, Dordrecht, The Netherlands, 666 pp., 1988.

van Heerwaarden, C. C. and Vilà-Guerau de Arellano, J.: Relative humidity as an indicator for cloud formation over heterogeneous land surfaces, J. Atmos. Sci., 65, 3263-3277, 2008.

Verzijlbergh, R. A., Jonker, H. J. J., Heus, T., and Vilà-Guerau de Arellano, J.: Turbulent dispersion in cloud-topped boundary layers, Atmos. Chem. Phys., 9, 1289-1302, doi:10.5194/acp-91289-2009, 2009.

Vilà-Guerau de Arellano, J., Kim, S.-W., Barth, M. C., and Patton, E. G.: Transport and chemical transformations influenced by shallow cumulus over land, Atmos. Chem. Phys., 5, 3219-3231, doi:10.5194/acp-5-3219-2005, 2005.

Wendisch, M., Hellmuth, O., Ansmann, A., Heintzenberg, J., Engelmann, R., Althausen, D., Eichler, H., Müller, D., Hu, M., Zhang, Y., and Mao, J.: Radiative and dynamic effects of absorbing aerosol particles over the Pearl River Delta, China, Atmos. Environ., 42, 6405-6416, 2008.

Wilde, N. P., Stull, R. B., and Eloranta, E. W.: The LCL zone and cumulus onset, J. Climate Appl. Meteorology, 24, 640-657, 
1985.

Williams, A. G. and Hacker, J. M.: The composite shape and structure of coherent eddies in the convective boundary layer, Bound.Lay. Meteorol., 61, 213-245, 1992.

Wulfmeyer, V. and Janjić, T.: Twenty-four-hour observations of the marine boundary layer using shipborne NOAA High-resolution Doppler lidar, J. Appl. Meteorol., 44, 1723-1744, 2005.

Wulfmeyer, V., Randall, M., Brewer, A., and Hardesty, R. M.: 2$\mu \mathrm{m}$ Doppler lidar transmitter with high frequency stability and low chirp, Opt. Lett., 25, 1228-1230, 2000.

Young, G. S.: Turbulence structure of the convective boundary layer. Part I: variability of normalized turbulence statistics, J. Atmos. Sci., 45, 719-726, 1988a.
Young, G. S.: Turbulence structure of the convective boundary layer. Part II: Phoenix 78 aircraft observations of thermals and their environment, J. Atmos. Sci., 45, 727-735, 1988 b.

Young, G. S.: Convection in the atmospheric boundary layer, EarthSci. Rev., 25, 179-198, 1988c.

Yu, H., Liu, S. C., and Dickerson, R. E.: Radiative effects of aerosols on the evolution of the atmospheric boundary layer, J. Geophys. Res., 107(D12), 4142, doi:10.1029/2001JD00754, 2002. 